\title{
An assessment of the sea breeze energy potential using small wind turbines in peri-urban coastal areas
}

\author{
Jordi Mazon $^{\mathrm{a}, \mathrm{b}}$, Jose I. Rojas ${ }^{\mathrm{b}}$, Jordi Jou ${ }^{\mathrm{b}}$, Aaron Valle ${ }^{\mathrm{b}}$, David Olmeda ${ }^{\mathrm{b}}$ and Carlos Sanchez \\ ${ }^{a}$ Department of Applied Physics, Universitat Politècnica de Catalunya (UPC BarcelonaTech) \\ email: jordi.mazon@upc.edu; T: +34 93 4134147; F: +34 934137007 \\ b Escola d'Enginyeria de Telecomunicació i Aerospacial de Castelldefels (EETAC), \\ Universitat Politècnica de Catalunya (UPC BarcelonaTech) \\ C/ Esteve Terradas 7, 08860, Castelldefels (Barcelona), Spain \\ Corresponding author email: josep.ignasi.rojas@upc.edu; T: +34 93 4134130; F: +34 93 \\ 4137007
}

\begin{abstract}
From wind speed data recorded hourly at $2 \mathrm{~m}$ high during 18 years (1993-2010) in the Llobregat Delta (15 km south of Barcelona city; northeast of the Iberian Peninsula), wind speed distributions at $10 \mathrm{~m}$ high were computed for the whole year and for the sea breeze period (from March 1 to September 30, from 10 to 19 local time). Weibull probability density functions fitted to the distributions were used to assess the wind energy generated by two offgrid small wind turbines: the IT-PE-100 and the HP-600W. Results from FAST and AeroDyn simulation tools were compared with those obtained by applying measured wind speeds to manufacturer power curves. Using manufacturer data, the IT-PE-100 would deliver $132 \mathrm{kWh}$ during the whole year (70 kWh during the sea breeze period). From the simulations, the IT-PE100 would deliver $155 \mathrm{kWh}$ during the whole year ( $80 \mathrm{kWh}$ during the sea breeze period). It is concluded that the sea-breeze is an interesting wind energy resource for micro-generation, not only in the Mediterranean basin but in other areas of the world with similar wind regimes, and particularly in peri-urban coastal areas where large-scale wind farms cannot be implemented.
\end{abstract}

Key words: sea breeze; Weibull; wind turbine; peri-urban areas; simulation 


\section{INTRODUCTION}

In the last decades, wind energy has become the most attractive renewable energy resource worldwide. Wind farms are widespread in areas where climatic conditions and topography features allow for their development. Traditionally, wind farms are installed in remote areas, where synoptic winds (i.e., winds associated to the meteorological macroscale) are significant. The large wind turbines used in typical wind farms, with tower heights that can be larger than $80 \mathrm{~m}$, have high efficiency in converting kinetic energy of horizontal synoptic wind into electric energy. However, more recently, interest in urban and suburban areas has raised as potential wind energy generation zones using small wind turbines. These areas are generally dominated by local winds (thermal winds) and are characterized by a lower potential productivity. Knowledge of the wind speed patterns in these areas is essential for enabling good assessments of wind energy generation. For this purpose, in the last years, research on the local regimes of winds has been intense [1]-[4]. There are also many investigations in the literature regarding wind farms in coastal sites [5]-[7]. Nevertheless, research on the simulation of potential wind energy generation from local winds is still scarce. Garvine et al. [8] investigated issues related to quantification of wind energy generated from the sea breeze. These researchers analyzed hourly wind records for a period of 18 years from meteorological stations in the US Middle Atlantic Bight, comparing areas of coast, estuary, and open shelf, and evaluating wind intensity at turbine hub-height due to the sea breeze compared with synoptic winds. These researchers concluded that the sea breeze regime is suitable for daily energy generation in the studied coastline regions, where the average wind speed is lower than $5.7 \mathrm{~m} \mathrm{~s}^{-1}$. They also found that, as expected, the wind energy generated from the sea breeze was larger offshore compared to onshore. Finally, to the authors knowledge there is no research in the literature on wind energy generation from the sea breeze in the Mediterranean basin.

The objective of this work is to analyze the wind energy generation from the sea breeze in the Llobregat Delta (15 km south of Barcelona city; northeast of the Iberian Peninsula), as an example of a regular and weak local wind regime, and to assess the potential of small wind turbines in the west Mediterranean basin. Ultimately, this research will clarify whether the sea breeze is adequate for energy generation using small wind turbines, what percentage of the produced annual wind energy would correspond to the sea breeze, and 
which types of small wind turbines are appropriate for wind energy generation from the sea breeze. In addition, the performance of FAST and AeroDyn simulation tools will be tested.

\subsection{The sea breeze regime}

The sea breeze is a thermal circulation exhibiting diurnal cycle within the local scale. Its dynamics have been studied by many researchers [9]-[13]. This circulation develops in coastal areas during daytime, caused by the differences between the air over the land (warmer) and the air over the sea (cooler). During daytime, especially around noon in the warm period (from March to September), the air over the land is heated faster (and therefore becomes less dense) than the air over the sea. The former gains altitude, while the air over the sea moves inland forming a cold front over the land. The air mass over the land that gained altitude travels hundreds of kilometers offshore, where a subsidence occurs, closing the thermal cycle. At night, the air over the land is cooled faster than the air over the sea, and another thermal circulation appears but reversed: the air over the land (cooler) travels offshore, while the air over the sea (warmer) gains altitude. This is the so-called land breeze circulation, much less intense than the sea breeze.

The sea breeze is generally less intense than synoptic winds. However, it features a larger periodicity, and thus a priori it could be suitable for energy generation with small wind turbines. Effectively, in many warm tropical areas the sea breeze shows high regularity, and maximum wind velocities around $7-8 \mathrm{~m} \mathrm{~s}^{-1}$ can be expected at low levels at noon and early afternoon [9]. Right after dawn and in the early morning, the sea breeze is weak and blows in a relatively thin atmosphere layer, having less than around $50 \mathrm{~m}$. Above this layer, the land breeze blows in the opposite direction. As the land-sea thermal difference increases during daylight, the thickness of the sea breeze layer increases, reaching 300-400 $\mathrm{m}$. The direction of the sea breeze exhibits diurnal rotation, especially on coastal zones, as a consequence of the Coriolis force. For instance, in the northern hemisphere, this force turns the sea breeze clockwise. In the Llobregat Delta, from March to September, the sea breeze blows from the southeast at the beginning of the day, while it blows from the southwest at the end of the day (see Subsection 3.1). Following this introduction, Section 2 is devoted to describe the methodology used in this research. Results are presented and discussed in Section 3. Finally, the conclusions are exposed in Section 4. 


\section{METHODOLOGY}

The quantification of the wind energy was obtained by means of several tools. First, two coupled software tools developed by the National Renewable Energy Laboratory (NREL) for aeroelastic simulation of horizontal-axis wind turbines (HAWT): FAST v7.01, a dynamics analysis code, and AeroDyn v13.00, an aerodynamics analysis routine capable of interfacing with FAST. In particular, the Fatigue, Aerodynamics, Structures, and Turbulence (FAST) code "is a comprehensive aeroelastic simulator capable of predicting both the extreme and fatigue loads of two- and three-bladed HAWT” [14]. AeroDyn is an element-level wind-turbine aerodynamics analysis routine that, when used in conjunction with dynamics software (e.g., FAST, YawDyn or SymDyn wind turbine dynamics analysis codes, or ADAMS ${ }^{\circledR}$ commercial dynamics analysis package), allows computing the aerodynamic loads on the blade elements of HAWT [15]. For this purpose, AeroDyn uses essentially two wake models: the blade element momentum (BEM) theory, and the generalized dynamic-wake theory, a model for skewed and unsteady wake dynamics [15]. Both models are used basically to calculate the axial induced velocities from the wake in the rotor plane, taking into account the influence of tip losses, hub losses and skewed wakes. AeroDyn uses also a dynamic stall model based on the semi-empirical Beddoes-Leishman model, and a tower shadow model based on potential flow around a cylinder and an expanding wake [16]. Since FAST and AeroDyn incorporate models of controller (servo) dynamics and structural (elastic) dynamics, they enable also simulation of the behavior of the control and protection systems and the structural dynamics [17]. It is worth to note that FAST and ADAMS ${ }^{\circledR}$, together with AeroDyn, were evaluated in 2005 by Germanischer Lloyd WindEnergie and found adequate for computation of loading of onshore wind turbines for design and certification [18].

FAST and AeroDyn were used in this research due to several reasons. First, these are wellknown, well-accepted codes, applied successfully in many previous investigations [17]. Second, FAST and AeroDyn are freeware (open access software), and it is possible to periodically download improvements of these tools. Finally, FAST and AeroDyn provide much flexibility in simulating modifications for optimizing wind turbine design, which is one of our future research objectives for the IT-PE-100. 
These tools require several input files containing diverse data like, for example, the windinflow conditions, and physical and aerodynamics parameters of the wind turbine blades. The first step of this research was to characterize the small wind turbines selected for this study and to build the input files requested by FAST and AeroDyn. This was done using the information and technical data provided by the manufacturers, and data measured from physical components, e.g., by 3D digitalization of the blades. For the aerodynamic, structural and/or control system properties lacking proper definition, the corresponding input data for the simulations were based on educated guesses.

QBlade was also used for double-checking the results obtained with the previous tools for the IT-PE-100. QBlade is open source software for design and simulation of HAWT, distributed under the GNU General Public License. Its integration in XFOIL allows airfoil design and airfoil performance analysis. QBlade allows also for extrapolation of airfoil performance data to $360^{\circ}$ angle of attack, turbine blade design, and realization of BEM simulations of the rotor and turbine. Finally, this tool allows structural blade design, modal and static loading analyses using QFem solver, generation of turbulent windfields, and realization of FAST simulations.

The off-grid small wind turbines selected for this research were the IT-PE-100 and the HP$600 \mathrm{~W}$. A summary of technical data is presented in Table 1. Both are 3-bladed upwind HAWT, and were selected mainly for the following reasons: 1 ) their start-up ${ }^{1}$ and cut-in ${ }^{2}$ wind speeds are relatively low (3 and $3.5 \mathrm{~m} \mathrm{~s}^{-1}$, respectively, for both), which makes them suitable for weak winds like the sea breeze; 2$)$ their dimensions are relatively small (10 m tower height; 1.7 and $1.5 \mathrm{~m}$ rotor diameter), which makes them suitable for urban and suburban areas, and areas close to an airport; and 3) we have recently installed the HP$600 \mathrm{~W}$ in the area of study, and we plan to install also the IT-PE-100. The latter is a $100 \mathrm{~W}$ wind turbine developed by Practical Action-Intermediate Technology Development Group (ITDG) to provide access to electricity to communities in rural or remote areas in developing countries. The turbine is especially suited to operate at low wind speeds, and was designed following the appropriate technology philosophy, i.e., it was intended to be simple, low-cost, robust, reliable, easy to maintain and, above all, producible by local workshops or microenterprises using a minimum of imported materials and components

\footnotetext{
${ }^{1}$ The start-up speed is the wind speed at which an unloaded rotor starts turning.

${ }^{2}$ The cut-in speed is the wind speed at which a wind turbine starts pushing power into the battery bank or the grid.
} 
[19], [20]. As an open access technology, the IT-PE-100 is not patented, and the design specifications, manuals and technical data by the manufacturers are available online [21], [22]. The blades and the hub are made of glass fiber reinforced polymer, and thus are light and with good structural properties. The turbine operates at high rotational speeds, nominally $420 \mathrm{rpm}$. This allows connecting the rotor shaft to the generator shaft directly, and makes unnecessary to devise a heavy transmission system [23]. The generator-rotor system is attached to the nacelle, a cylindrical piece of steel inserted in the upper end of the tower. The nacelle allows rotation of the rotor-generator system around its vertical axis, facilitating alignment with the wind.

The second wind turbine analyzed in this work, the HP-600W, was developed by Hopeful Energy, a manufacturer specialized in low-wind speed turbines. This turbine is light, compact and smaller than most low-wind speed turbines and small wind turbines. The blades are made of nylon and glass fiber reinforced polymer, specially coated to prevent problems due to corrosion, high temperatures, water, salinity, dust and sand. The HP-600W is designed to work nominally at higher wind speeds compared to the IT-PE-100, i.e., $12 \mathrm{~m}$ $\mathrm{s}^{-1}$ of rated wind speed for $600 \mathrm{~W}$ of rated output power, versus $6.5 \mathrm{~m} \mathrm{~s}^{-1}$ of rated wind speed for $100 \mathrm{~W}$ of rated output power. Like the IT-PE-100, the HP-600W has an axialflux permanent magnet synchronous generator [23], [24], but it works at higher rotational speed, nominally 810 rpm.

Table 1 Summary of technical data of the IT-PE-100 and the HP-600W wind turbines.

\begin{tabular}{|c|c|c|}
\hline Concept & IT-PE-100 & HP-600W \\
\hline Rated output power & $100 \mathrm{~W}$ & $600 \mathrm{~W}$ \\
\hline Rotor configuration & 3 blades, upwind, horizontal-axis & 3 blades, upwind, horizontal-axis \\
\hline Control & Variable speed, furling tail & No information available \\
\hline Blades & Fixed-pitch, NACA 4412 airfoils & No information available \\
\hline Drive train & High speed, direct coupling & No information available \\
\hline Rotor diameter & $1.7 \mathrm{~m}$ & $1.5 \mathrm{~m}$ \\
\hline Blade length & $0.7 \mathrm{~m}$ & $0.68 \mathrm{~m}$ \\
\hline Hub diameter & $0.3 \mathrm{~m}$ & $0.14 \mathrm{~m}$ \\
\hline Hub-height & $8-10 m$ & $8-10 m$ \\
\hline Start-up wind speed & $3 \mathrm{~m} \mathrm{~s}^{-1}$ & $3 \mathrm{~m} \mathrm{~s}^{-1}$ \\
\hline Cut-in wind speed & $3.5 \mathrm{~m} \mathrm{~s}^{-1}$ & $3.5 \mathrm{~m} \mathrm{~s}^{-1}$ \\
\hline Rated wind speed & $6.5 \mathrm{~m} \mathrm{~s}^{-1}$ & $12 \mathrm{~m} \mathrm{~s}^{-1}$ \\
\hline Maximum wind speed & $12 \mathrm{~m} \mathrm{~s}^{-1}$ & $25 \mathrm{~m} \mathrm{~s}^{-1}$ \\
\hline Rated rotor rotational speed & 420 rpm & 810 rpm \\
\hline
\end{tabular}




\section{RESULTS \& DISCUSSION}

Since FAST and AeroDyn require data on the wind-inflow conditions, the next step after characterization of the wind turbines was to calculate the wind speed distribution in the area under study, from the wind data measured in situ in the period 1993-2010. This process is explained in Subsection 3.1. Following this subsection, the results on power production, energy generation and power coefficients obtained from FAST and AeroDyn and applying manufacturer power curves are presented and discussed.

\subsection{Wind speed distribution \& prevailing wind direction}

The Catalan Weather Service (MeteoCat) has an automatic weather station in the Llobregat Delta since 1993. Every 10 minutes, the station averages and records the wind speed and direction at $2 \mathrm{~m}$ high, among other meteorological parameters. The data available to the users are the hourly averages of these records. For this research, all the data sets recorded in the period 1993-2010 were used. Assuming a stable atmosphere and a roughness length of 0.25 , which corresponds to open landscape and areas with scattered shelter belts [25], the wind speed at $10 \mathrm{~m}$ high was computed from the data acquired by the station using the classical potential wind equation:

$$
V_{H}=V_{2 m} \times \frac{\ln \left(\frac{H}{z_{0}}\right)}{\ln \left(\frac{2}{z_{0}}\right)}
$$

where $V_{H}$ is the velocity at the height $H, V_{2 m}$ is the wind speed measured at $2 \mathrm{~m}$ height, and $z_{0}$ is the roughness length. Next, the Weibull probability density function was fitted to the wind speed data at $10 \mathrm{~m}$ high. Fig. 1 shows the Weibull distribution resulting from the fitting to the wind speed data for the whole year (from January 1 to December 31, from 00 to 24 local time (LT), for 1993-2010). This Weibull curve has a shape factor $k$ of 1.51 and a scale factor $C$ of 3.01. The highest probabilities are centered at very low velocities. Particularly, the peak of probability, $12.4 \%$, is obtained for a wind speed of $1.5 \mathrm{~m} \mathrm{~s}^{-1}$; and the probability for the wind speed to be lower than $3 \mathrm{~m} \mathrm{~s}^{-1}$ (the start-up wind speed for the studied turbines) is $63.1 \%$. Fig. 2 shows the Weibull distribution resulting from the fitting to the wind speed data for the sea breeze period (from March 1 to September 30, from 10 to 19 LT, for 1993-2010). This Weibull curve has a shape factor $k$ of 1.80 and a scale factor $C$ 
of 4.23. In this case, the peak of probability, 9.5\%, is shifted towards a higher wind speed of $2.7 \mathrm{~m} \mathrm{~s}^{-1}$; and the probability for the wind speed to be lower than $3 \mathrm{~m} \mathrm{~s}^{-1}$ is $41.6 \%$. Weibull distributions with shape factors around 2 are typical for wind speeds in north European sites, particularly in good rural and high rise sites, while for building-mounted sites the shape factor tends to be lower than 2 [26]. Summarizing, wind speeds are higher than the start-up speed 3232 hours during the whole year (36.9\% of the total number of hours between 00 and 24 LT from January 1 to December 31) and 1250 hours during the sea breeze period (58.4\% of the total number of hours between 10 and 19 LT from March 1 to September 30).

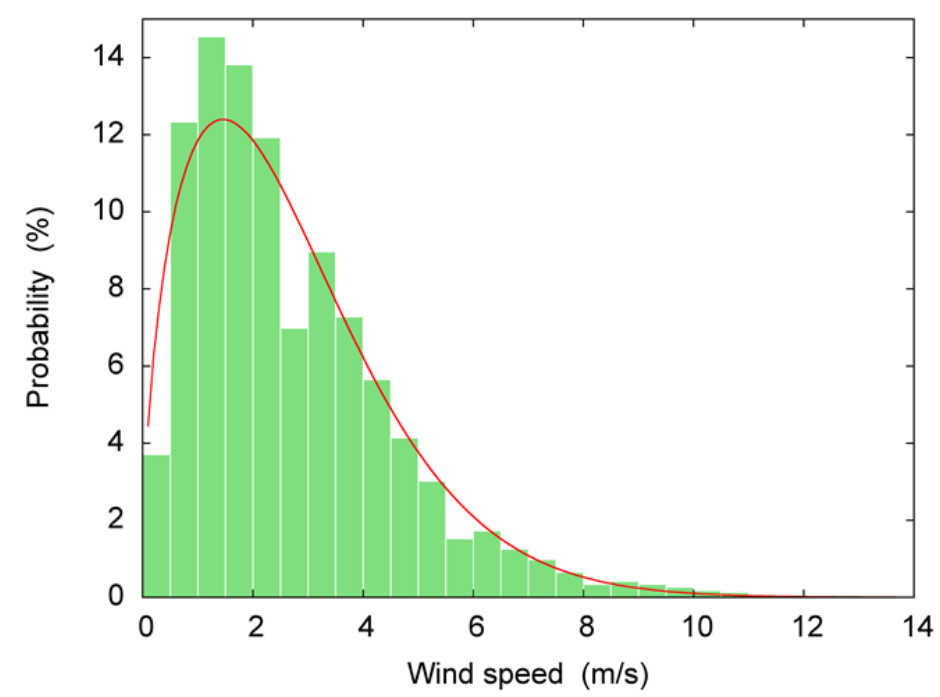

Fig. 1. Wind speed distribution computed from measured wind speed data, and fitted Weibull probability density function for the whole year period (from January 1 to December 31, from 00 to 24 LT, for 1993-2010). 


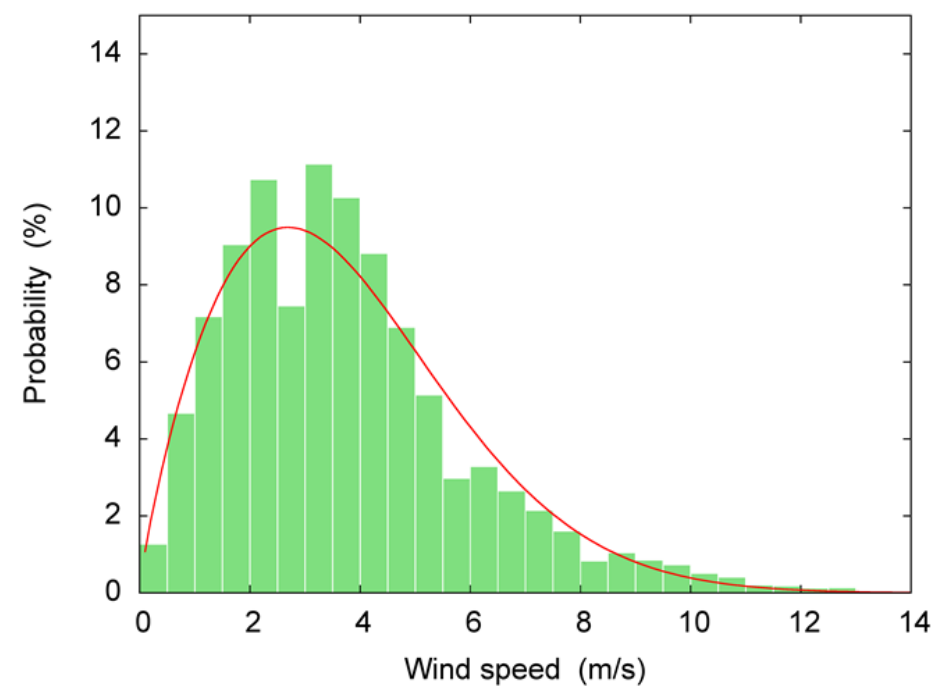

Fig. 2. Wind speed distribution computed from measured wind speed data, and fitted Weibull probability density function for the sea breeze period (from March 1 to September 30, from 10 to 19 LT, for 1993-2010).

As per the dominant wind directions in the Llobregat Delta, from the data recorded by the weather station from 1993 to 2010, the northern and southern directions prevail when considering either the whole year or the period from March 1 to September 30 . Wind directions ranging from NW to NE represent $45 \%$ of the total measurements for the whole year (53\% of the measurements from March to September), while wind directions ranging from SW to SE represent 38\% (40\% of the measurements from March to September). Considering now the data from March to September, but only within the studied sea breeze time during the day (from 10 to 19 LT), instead of the whole day, the dominant direction is SW, which corresponds to the sea breeze circulation. Superposed to this circulation, there are some minor contributions of winds caused by other atmospheric events, such as advections, low pressure systems, largescale fronts, etc. But in any case, it is clear that the prevailing winds over the Llobregat Delta during the so-called sea breeze period (from March 1 to September 30, from 10 to 19 LT) are basically associated to sea breeze circulations. Thus, according to this analysis, it can be assumed that the wind energy generated during the sea breeze period is basically due to the sea breeze.

Finally, if abundant reliable measurements of wind speed in the geographical area of study were not available, estimation of the power and energy generation using the 
procedure proposed in this work is still possible. It would only be necessary to first obtain predictions of wind speed using one or more of the various well accepted tools for micro-scale wind resource assessment [27], [28]. The use of these tools is a de-facto standard, for example, in wind farm design [29].

\subsection{Power production}

The power and energy generated by the IT-PE-100 and HP-600W were computed by means of FAST and AeroDyn. To evaluate the relative importance of the sea breeze, power and energy generated were quantified independently both in the whole year period and in the sea breeze period. One of the most common and easiest ways to analyze the performance of a wind turbine is to obtain the power produced as a function of the wind speed for a set of simplified load scenarios. This provides a relatively good approach on how the turbine works, but it can be misleading as well, since the probability of a power value occurring during a time period should also be taken into account.

There are several methods to obtain the probability distribution of the power produced [30]. The well-known static method was used in this research because of its simplicity, as it ignores non-stationary effects, i.e., losses due to changes in wind direction and maintenance periods. The static method is based on the principle that the probability density function of the power produced follows a Weibull curve with the same scale and shape factors as the Weibull curve corresponding to the wind speed distribution the power originated from, i.e., both probability density functions are two identical Weibull curves. Therefore, to obtain the probability for a given output power to be generated by a wind turbine, we just need to superpose the Weibull distribution of the wind speed and the output power curve. In particular, Fig. 3 and Fig. 4 show the manufacturer power curves and the power curves obtained from FAST and AeroDyn for the IT-PE-100 and HP-600W, respectively, together with the Weibull distributions for the sea breeze period and the whole year period, as a function of the wind speed.

The interpretation of Fig. 3 and Fig. 4 is easy. If we consider the Weibull probability density function for the whole year period, for example, the probability for the wind speed to be $3.5 \mathrm{~m} \mathrm{~s}^{-1}$ is around $7.7 \%$. From the simulated power curve for the IT-PE-100 
(see Fig. 3), this wind speed corresponds to an output power of around $20 \mathrm{~W}$. Thus, according to the static method, this means that the probability for the IT-PE-100 to provide $20 \mathrm{~W}$ at any time of the year is $7.7 \%$. If we now consider the Weibull probability density function for the sea breeze period, the probability for the wind speed to be $3.5 \mathrm{~m} \mathrm{~s}^{-1}$, and thus for the IT-PE-100 to provide $20 \mathrm{~W}$, increases to around $9.0 \%$.

On the other side, from the simulated power curve for the HP-600W (see Fig. 4), a wind speed of $3.5 \mathrm{~m} \mathrm{~s}^{-1}$ corresponds to a simulated output power of around $13 \mathrm{~W}$.

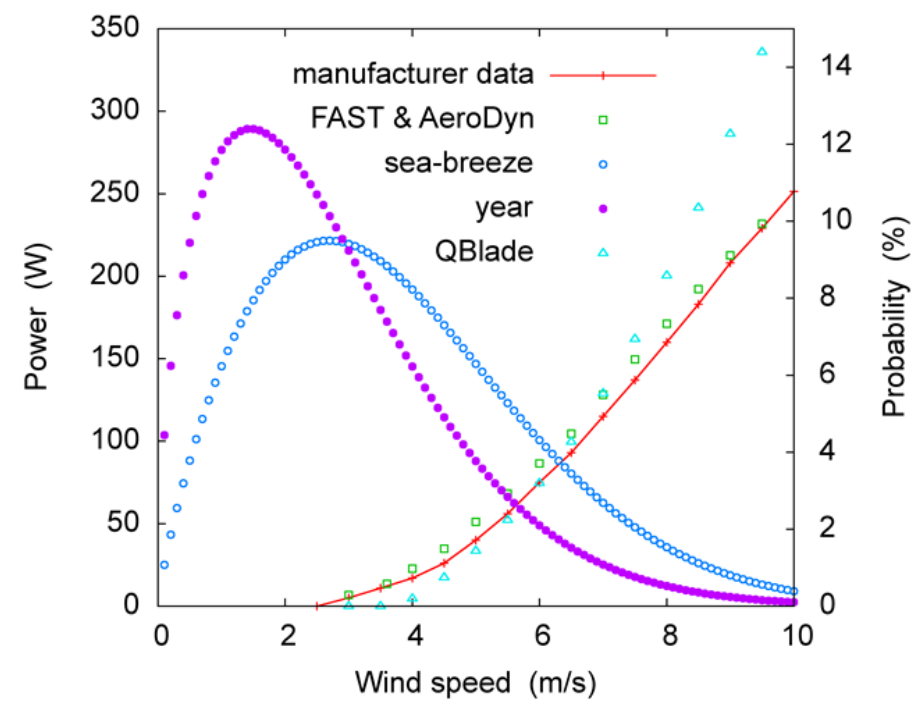

Fig. 3. Manufacturer power curves and power curves obtained from FAST and AeroDyn, and from QBlade, together with Weibull distributions for the whole year period and sea breeze period, for the IT-PE-100.

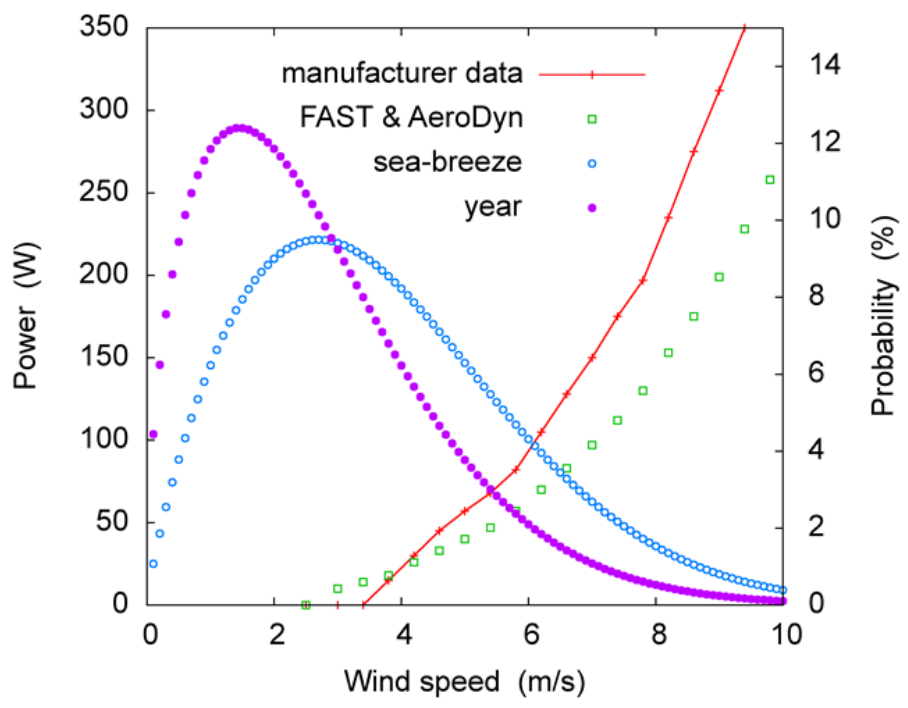

Fig. 4. Manufacturer power curves and power curves obtained from FAST and AeroDyn, together with Weibull distributions for the whole year period and sea breeze period, for the HP-600W. 
The relative error between the manufacturer power curve and the power curve from FAST and AeroDyn is $10.1 \pm 13.3 \%$ for the IT-PE-100 and $-28.4 \pm 2.9 \%$ for the HP$600 \mathrm{~W}$. The error is associated to inaccuracies and limitations of the wind turbine models, intrinsic limitations of the models used by FAST and AeroDyn to solve the aeroelastic problem, and inaccuracies of the manufacturer power curves. For the HP$600 \mathrm{~W}$, the output power from the simulations is lower than the manufacturer power curve. This is expected, as suppliers of commercial turbines typically provide overoptimistic performance data of their products. Conversely, for the IT-PE-100, which is an open access technology, the output power from the simulations is higher than the manufacturer power curve. According to the results from the simulations, the IT-PE-100 produces more power at low wind speeds than the HP-600W, while the contrary occurs if we consider the manufacturer power curves. The average error is larger for the commercial HP-600W, as expected, since less design and technical data essential for the modeling of the turbine was available. Hence, we were forced to make more use of educated guesses when preparing the FAST and AeroDyn input files for the HP-600W. Also, the power curves agree more closely with manufacturer data at low wind speeds, while a tailing off trend is observed at high wind speeds, especially for the HP-600W. This phenomenon has also been reported for other turbines in a previous work [26]. Finally, the IT-PE-100 power curve obtained from QBlade shows also deviations compared to manufacturer data, with the power being underestimated (overestimated) below (above) a wind speed of around $6 \mathrm{~m} / \mathrm{s}$.

\subsection{Energy generation}

Using the data summarized in Fig. 3 and Fig. 4, i.e., the probability density functions of the output power, and considering a start-up wind speed of $3 \mathrm{~m} \mathrm{~s}^{-1}$, we computed the average annual power and energy generated by the selected wind turbines both for the whole year and the sea breeze period. The results are presented in Table 2. Note that energy generation predictions obtained from FAST and AeroDyn, and from QBlade, are compared with predictions obtained by applying measured wind speeds to manufacturer power curves. The discrepancies observed in the power curve obtained from QBlade (see Fig. 3) seem to be balanced for the sea breeze period, as the results derived from QBlade for average annual power and energy generated by the IT-PE-100 are half way between those obtained using 
manufacturer data and FAST and AeroDyn. On the other side, the results derived from QBlade for the whole year period are slightly lower than those obtained using manufacturer data. The reason is that the underestimation of output power by QBlade for wind speeds below $6 \mathrm{~m} / \mathrm{s}$ is now dominant, since the probability of the wind speed to be lower than 6 $\mathrm{m} / \mathrm{s}$ is much higher in the whole year period compared to the sea breeze period.

Table 2 Average output power and energy generated by the IT-PE-100 ( $P_{100}$ and $\left.E_{100}\right)$ and the HP-600W $\left(P_{600}\right.$ and $\left.E_{600}\right)$ for the sea breeze period and the whole year period, obtained from FAST and AeroDyn, from QBlade, and applying measured wind speeds to manufacturer power curves.

\begin{tabular}{lllll}
\hline Period & $P_{100}(\mathrm{~W})$ & $P_{600}(\mathrm{~W})$ & $E_{100}(\mathrm{kWh})$ & $E_{600}(\mathrm{kWh})$ \\
\hline Sea breeze (FAST \& AeroDyn) & 37 & 33 & 80 & 70 \\
Whole year (FAST \& AeroDyn) & 18 & 15 & 155 & 134 \\
\hline Sea breeze (QBlade) & 35 & - & 74 & - \\
Whole year (QBlade) & 14 & - & 123 & - \\
\hline Sea breeze (manufacturer) & 33 & 45 & 70 & 96 \\
Whole year (manufacturer) & 15 & 20 & 132 & 170 \\
\hline
\end{tabular}

These values are similar to those presented in the Warwick Wind Trials Project (WWTP) final report [26]. The objective of this project was to measure the energy generated by building-mounted, grid connected small wind turbines [31]. Wind turbines from five UK manufacturers (with rated powers from 400 to $1250 \mathrm{~W}$ ) were tested in 26 different sites. The average measured wind speed in the sites ranged from 1.7 to $6.7 \mathrm{~m} \mathrm{~s}^{-1}$, and the average measured energy generated per turbine per year was $78 \mathrm{kWh}$. If the periods when turbines are switched off for maintenance or due to failures are not taken into account, this average rises to $230 \mathrm{kWh}$ per year, or just $94 \mathrm{kWh}$ per year, if the results corresponding to the best site (a very exposed rural location) and very high buildings are omitted. The turbine in the poorest site generated an average of $15 \mathrm{kWh}$ per year, which is less than the energy consumed by the turbine's electronics. We must also bear in mind that, as wind speed data and manufacturer power curves are often not very accurate, it is not uncommon to obtain energy predictions with errors larger than $\pm 25 \%$ if data were not significantly adjusted prior to calculations. For instance, using measured wind speed data and manufacturer power curves can lead to overestimating energy output by a factor between 1.7 and 3.4 [26].

The Llobregat Delta is basically a suburban area, characterized by the presence of farms, secondary roads and paths between cities, and a $20 \mathrm{~km}$ long promenade following the coastline. The selected turbines have small rotor diameters, and hubheights equivalent to a street light. Thus, a number of these small wind turbines could 
be installed integrated in the lighting systems besides the roads, paths and the sea-shore promenade, ultimately operating as a wind farm. As a quick example, a thousand ITPE-100 turbines would provide 155 MWh per year according to the manufacturer power data. This energy could be used for many purposes, like feeding the lighting systems. For instance, each IT-PE-100 could feed two 25 W LED lamps 8.5 hours per day during one year. Also, to water their crops, at present day many farmers in the area use fuel pumps to extract water from the aquifer. Instead, they could use electric pumps fed by these small wind turbines [32], [33].

\subsection{Power coefficient}

For wind turbines, the power coefficient $C_{P}$ is defined as the ratio between the turbine output power $P_{\text {out }}$ and the available wind kinetic power $P_{a v}$ for a given wind speed $V$ [30]. The power coefficient measures the efficiency of the wind turbine in converting the wind kinetic energy into electric energy, and cannot exceed 0.5925, the so-called Betz limit [34]. The available wind kinetic power can be computed with the following expression:

$$
P_{a v}=\frac{1}{2} \dot{m} V^{2}=\frac{1}{2} \rho A V^{3}
$$

where $\dot{m}$ is the air mass flow, $\rho$ is the air density and $A$ is the rotor area. Fig. 5 shows the power coefficient as a function of the wind speed for the IT-PE-100 and the HP-600W, computed by applying manufacturer power data, on one side, and output power results from FAST and AeroDyn simulations, on the other side. The HP-600W is able to provide power in a wider range of wind speeds (up to $25 \mathrm{~m} \mathrm{~s}^{-1}$ instead of only $12 \mathrm{~m} \mathrm{~s}^{-1}$ ), and is more efficient, i.e., has higher power coefficient for all relevant wind speeds, according to the manufacturer data. But when considering the results from the simulations, it appears that the IT-PE-100 would be more efficient at wind speeds ranging from 5 to $7.5 \mathrm{~m} \mathrm{~s}^{-1}$. For the HP-600W, a large deviation between the manufacturer and modelled estimates of the power coefficient can be observed in Fig. 5. This is due to the large relative error between the manufacturer power curve and the power curve from FAST and AeroDyn for the HP600W. As mentioned in Subsection 3.2, the large error in the simulations is due to, inter alia, the fact that we lacked many design and technical data essential for the modeling of the HP-600W, as this is a commercial product and most of this information is confidential. 


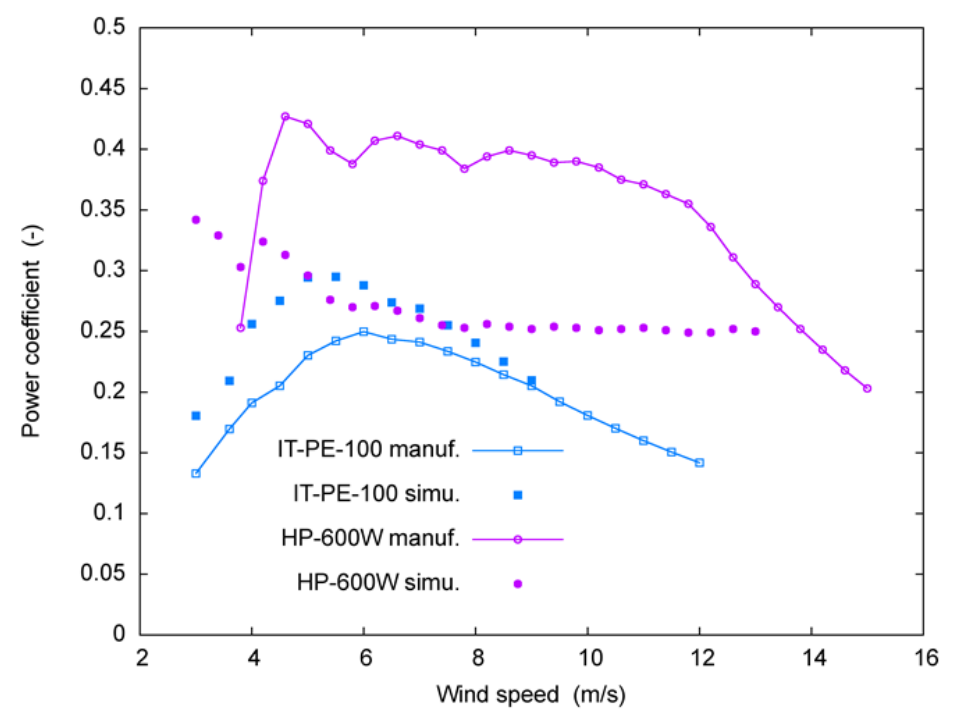

Fig. 5. Power coefficient vs. wind speed obtained from FAST and AeroDyn, and applying manufacturer power data, for the IT-PE-100 and HP-600W wind turbines.

It is worth noting that Colet-Subirachs et al. [18] developed a control algorithm for the IT-PE-100 to run constantly at its peak power coefficient. For all the simulated operating conditions, the turbine with this simple open-loop control ran at a power coefficient of approximately 0.37 . On the contrary, for the IT-PE-100 operating as part of a conventional constant DC system, the power coefficient had an average value of 0.24 and did not exceed 0.30 in most simulations. Our results for the IT-PE-100 are in agreement with that research, as the average power coefficient is 0.20 and the maximum power coefficient is 0.25 , if we consider the manufacturer power data, or 0.25 and 0.30 , respectively, if we consider the results from the simulations. If we implemented ColetSubirachs' control algorithm for the IT-PE-100, assuming a constant power coefficient of 0.37 for all wind speeds from 3 to $12 \mathrm{~m} \mathrm{~s}^{-1}$, the figures presented in Table 2 for the IT-PE-100 would increase significantly. The average annual power would be $26 \mathrm{~W}$, for a total energy generation of $228 \mathrm{kWh}$ per year. During the sea breeze period, the average power would be $56 \mathrm{~W}$, for a total energy generation of $121 \mathrm{kWh}$ per year. Therefore, the implementation of Colet-Subirachs' control algorithm for the IT-PE-100 would make this turbine very appropriate for applications in the Llobregat Delta, providing increased average output power and total energy. 


\section{CONCLUSIONS}

The wind energy generated by the IT-PE-100 and HP-600W small wind turbines in the Llobregat Delta (15 km south of Barcelona city; northeast of the Iberian Peninsula) was analyzed. The Llobregat Delta is characterized by low-speed winds throughout the whole year, as confirmed by wind speed data recorded hourly since 1993. In particular, the sea breeze (a thermal wind) dominates from spring to autumn. Energy generation predictions obtained using FAST and AeroDyn simulation tools were compared with predictions obtained by applying measured wind speeds to manufacturer power curves. The wind turbines would provide around $150 \mathrm{kWh}$ during the whole year. In all the studied cases, more than $50 \%$ of the total annual energy would be generated during the sea breeze period. In view of these results, it is concluded that the sea-breeze is interesting as a wind energy resource for micro-generation.

As a collateral result, FAST and AeroDyn have been tested for simulation of small wind turbines operating in low wind speed conditions. For the IT-PE-100, the accuracy of the simulations is satisfactory and thus these software tools have proven adequate to obtain useful energy predictions. It may not seem so for the HP-600W, but there was a lack of many design and technical data essential for the proper modeling of the turbine. A number of small wind turbines could be installed integrated in lighting systems besides roads, paths and a $20 \mathrm{~km}$ long sea-shore promenade in the Llobregat Delta. The energy generated could be used for many purposes, e.g., to feed lighting systems or electric pumps to extract water from the aquifer. Finally, it is our intention to take in situ measurements of power and energy generated by the IT-PE-100 and HP-600W, to validate the simulations. By the time this paper is submitted, an HP-600W has already been installed in the area of study, but still no measurements are available.

\section{Acknowledgements}

The wind speed and direction data were provided by the Catalan Weather Service (MeteoCat). We acknowledge the valuable help by the Grup de Recerca en Cooperació $i$ Desenvolupament Humà (Research Group on Cooperation and Human Development, GRECDH) of the Universitat Politècnica de Catalunya (UPC BarcelonaTech). The 3D 
digitalization of the blades of the HP-600W was funded by the Department of Environment of the City Council of Viladecans.

\section{References}

[1] S. Bivona, R. Burlon, and C. Leone, "Hourly wind speed analysis in Sicily," Renew. Energy, vol. 28, no. 9, pp. 1371-1385, 2003.

[2] J. A. Carta and P. Ramirez, "Analysis of two-component mixture Weibull statistics for estimation of wind speed distributions," Renew. Energy, vol. 32, no. 3, pp. 518-531, 2007.

[3] A. N. Celik, A. Makkawi, and T. Muneer, "Critical evaluation of wind speed frequency distribution functions,” J. Renew. Sustain. Energy, vol. 2, no. 1, p. 13102, 2010.

[4] A. W. Dahmouni, M. Ben Salah, F. Askri, C. Kerkeni, and S. Ben Nasrallah, "Wind energy in the Gulf of Tunis, Tunisia," Renew. Sustain. Energy Rev., vol. 14, no. 4, pp. 1303-1311, 2010.

[5] G. J. Dalton, D. A. Lockington, and T. E. Baldock, "Feasibility analysis of standalone renewable energy supply options for a large hotel,” Renew. Energy, vol. 33, no. 7, pp. 1475-1490, 2008.

[6] A. Montlaur, S. Cochard, and D. F. Fletcher, "Formation of tip-vortices on triangular prismatic-shaped cliffs. Part 2: A computational fluid dynamics study,” J. Wind Eng. Ind. Aerodyn., vol. 109, pp. 21-30, 2012.

[7] M. S. Mason, G. S. Wood, and D. F. Fletcher, "Numerical investigation of the influence of topography on simulated down burst wind fields," J. Wind Eng. Ind. Aerodyn., vol. 98, pp. 21-33, 2010.

[8] R. W. Garvine and W. Kempton, “Assessing the wind field over the continental shelf as a resource for electric power,” J. Mar. Res., vol. 66, no. 6, pp. 751-773, 2008.

[9] J. E. Simpson, Sea Breeze and Local Winds. Cambridge, UK: Cambridge University Press, 1994, p. 234.

[10] R. Rotunno, "On the linear-theory of the land and sea breeze,” J. Atmos. Sci., vol. 40, no. 8, pp. 1999-2009, 1983.

[11] M. A. Estoque, “A theoretical investigation of the sea breeze,” Q. J. R. Meteorol. Soc., vol. 87, no. 372, pp. 136-146, 1961.

[12] D. G. Steyn and G. Kallos, "A study of the dynamics of hodograph rotation in the sea breezes of Attica, Greece,” Boundary-Layer Meteorol., vol. 58, no. 3, pp. 215-228, 1992. 
[13] R. W. Arritt, "Effects of the large-scale flow on characteristic features of the sea breeze,” J. Appl. Meteorol., vol. 32, no. 1, pp. 116-125, 1993.

[14] J. M. Jonkman and M. L. Buhl, “FAST User’s Guide - Technical Report NREL/EL-500-38230.” National Renewable Energy Laboratory (NREL), Golden, CO, USA, 2005.

[15] D. J. Laino and A. C. Hansen, "User's Guide to the Wind Turbine Dynamics Aerodynamics Computer Software AeroDyn.” Windward Engineering, LLC, Salt Lake City, UT, USA, 2002.

[16] P. J. Moriarty and A. C. Hansen, “AeroDyn Theory Manual - Technical Report NREL/EL-500-36881,” National Renewable Energy Laboratory (NREL), Golden, CO, USA, 2005.

[17] J. M. Jonkman and D. Matha, "Dynamics of offshore floating wind turbinesanalysis of three concepts,” Wind Energy, vol. 14, no. 4, pp. 557-569, 2011.

[18] A. Manjock, "Evaluation Report: Design Codes FAST and ADAMS® for Load Calculations of Onshore Wind Turbines - Report No. 72042,” Germanischer Lloyd WindEnergie GmbH, Humburg, Germany, 2005.

[19] L. Ferrer-Marti, A. Garwood, J. Chiroque, R. Escobar, J. Coello, and M. Castro, "A community small-scale wind generation project in Peru," Wind Eng., vol. 34, no. 3, pp. 277-288, 2010.

[20] L. Ferrer-Marti, A. Garwood, J. Chiroque, B. Ramirez, O. Marcelo, M. Garfi, and E. Velo, "Evaluating and comparing three community small-scale wind electrification projects,” Renew. Sustain. Energy Rev., vol. 16, no. 7, pp. 53795390, 2012.

[21] H. Piggott, “The Permanent Magnet Generator (PMG): A manual for manufacturers and developers.” Scoraig Wind Electric, Scotland, UK, p. 27, 2001.

[22] T. Sanchez, S. Fernando, and H. Piggott, "Wind rotor blade construction - Small wind systems for battery charging.” ITDG, UK, p. 51, 2001.

[23] A. Colet-Subirachs, O. Gomis-Bellmunt, D. Clos-Costa, G. Martin-Segura, A. Junyent-Ferre, R. Villafafila-Robles, and L. Ferrer-Marti, "Electromechanical modelling and control of a micro-wind generation system for isolated low power DC micro grids,” Eur. Power Electron. Drives Assoc. J., vol. 20, no. 2, pp. 4248, 2010.

[24] J. F. Gieras, R. J. Wang, and M. J. Kamper, Axial Flux Permanent Magnet Brushless Machines, 1st ed., Dordrecht, The Netherlands: Springer Netherlands, 2004, p. 310. 
[25] H. Moalic, J. A. Fitzpatrick, and A. A. Torrance, "The correlation of the characteristics of rough surfaces with their friction coefficients,” Proc. Inst. Mech. Eng. Part C-Journal Mech. Eng. Sci., vol. 201, no. 5, pp. 321-329, 1987.

[26] D. Hailes, “Warwick Wind Trials Project (WWTP) final report,” Encraft, Warwick, UK, 2009.

[27] S. K. Khadem and M. Hussain, "A pre-feasibility study of wind resources in Kutubdia Island, Bangladesh,” Renew. Energy, vol. 31, no. 14, pp. 2329-2341, 2006.

[28] M. Ranaboldo, L. Ferrer-Marti, and E. Velo, "Micro-scale wind resource assessment for off-grid electrification projects in rural communities. A case study in Peru,” Int. J. Green Energy, vol. 11, pp. 75-90, 2014.

[29] L. Landberg, L. Myllerup, O. Rathmann, E. L. Petersen, B. H. Jorgensen, J. Badger, and N. G. Mortensen, "Wind resource estimation - An overview," Wind Energy, vol. 6, no. 3, pp. 261-271, 2003.

[30] T. Burton, D. Sharpe, N. Jenkins, and E. Bossanyi, Wind Energy Handbook, vol. 2 ed. Chichester, UK: John Wiley \& Sons, Ltd., 2011, p. 742.

[31] R. Walters and P. R. Walsh, "Examining the financial performance of microgeneration wind projects and the subsidy effect of feed-in tariffs for urban locations in the United Kingdom,” Energy Policy, vol. 39, no. 9, pp. 5167-5181, 2011.

[32] O. Ozgener, "Use of solar assisted geothermal heat pump and small wind turbine systems for heating agricultural and residential buildings,” Energy, vol. 35, no. 1, pp. 262-268, 2010.

[33] A. M. De Broe, S. Drouilhet, and V. Gevorgian, "A peak power tracker for small wind turbine in battery charging applications," IEEE Trans. Energy Convers., vol. 14, no. 4, pp. 1630-1635, 1999.

[34] A. Betz, Introduction to the Theory of Flow Machines. Oxford, UK: Pergamon Press, 1966. 